\title{
An Action Day for First-Semester Students, fostering Self-Reflection, Networking and many other Skills
}

\section{Zehetmeier, Daniela $^{a}$; Thurner, Veronika ${ }^{a}$ and Böttcher, Axel ${ }^{\mathrm{a}}$}

${ }^{a}$ Department of Computer Science and Mathematics, Munich University of Applied Sciences, Germany

\begin{abstract}
Over the years, we observed that students have difficulties when moving from school to university. In order to support our first-semester students, we designed and performed an action day at the beginning of their first semester. This day is designed to create identification with the subject, to get them actively engaged, and to let students get in contact with each other in an unstressed atmosphere. Furthermore, we intend to assess students' initial level of competences relevant for studying successfully. The first four applications achieved good results. Passive students turned to a more active attitude, as they understood that they are responsible for their academic success right from the beginning. In a survey the majority of students agreed that the action day helped to get in contact with their fellow students. Interviews with lecturers confirmed this statement. Moreover, through the assessments, lecturers get insights into their students' competences at a very early stage. This helps to adjust the teaching to students' needs or offer additional support to them. Taken together, we designed an approach that offers our students a better start into their life at our university and we will continue performing this action day.
\end{abstract}

Keywords: First-semester students, engineering education, competences, socialising, assessments, university entry-phase. 


\section{Introduction}

For a number of years, many lecturers have observed that students struggle during the first semesters of their studies. Nevertheless, the reasons for these struggles are still not clearly understood. As a consequence, lecturers are unsure of how to best support their students.

To improve the situation, we designed an action day for our students that takes place right at the beginning of their studies. During this day, we involve students in project tasks that create identification with the subject of their studies, and get them actively engaged at the same time. In between, we incorporate two assessments that evaluate initial competences that are relevant for successfully studying Computer Science or related topics. Thus, we help students to become aware of what it takes to study successfully (according to Thurner (2012)), and to assess how well they are set up for this task.

So far, we applied our action day concept four times, achieving good results. For example, students that participated in the action day adopted a more active attitude in their studies, accepting their own responsibility for the success of their studies at an early stage of their study process. As well, observing students throughout the action day and analysing assessment results helps lecturers to quickly understand the existing skills in their cohorts as well as issues where students need more specific support.

\section{Goals}

Many difficulties that students are confronted with when moving from school to university are caused by the different understanding of education and learning processes that prevail within these types of institution. For example, while schools in Germany mainly focus on learning facts and processes by heart, universities focus on deep understanding and problem solving abilities. Furthermore, schools provide precisely defined activities that students are supposed to follow, closely following instructions and not deviating from these welltrodden paths. In contrast to this, universities expect students to identify and organize their own individual way of learning and practicing, thus studying actively rather than "being studied" by the lecturers. As a consequence, students that were well adapted to school do not necessarily possess those key competencies that are relevant for successfully studying at university. Thus, we aim at making students aware of these study requirements and their own initial skills, right at the beginning of their studies.

Furthermore, we want to provide a setting where students can easily get into contact with each other, building teams and creating networks right from the start. Being well connected socially within the student group helps students to cope with the challenging demands of the study process and thus has a positive impact on both motivation and retention. As well, the first days of their studies should be intense and interesting at the same time. 


\section{Related Work}

In a first step, we evaluated existing study-entry programs and analysed both their benefits and their limits. Then, we designed two assessments that provide insight into our first-year students' initial competences. Finally, we combined these two approaches into an action day for first term students.

\subsection{Various study-entry programs}

Many other universities world-wide try to increase students motivation, foster socialising and to reduce deficiencies in specific knowledge areas, in order to reduce drop-out rates right at the beginning. Almost all attempts in this area are time consuming, thus reducing lecture time, which in turn diminishes the willingness of lecturers to participate in such an activity with their students. Additionally, these concepts often need a large staff including experienced lecturers, which are harder to recruit than student tutors.

Some entry programs such as Reith (2015), Rothe (2015) and Standridge (2016) combine lectures and small projects, with a duration from several days up to the whole first semester. Usually, these programs aim at connecting theoretical input and its practical applications, as it will occur later on the job.

Another approach was developed by Diehl et al. (2016) at OTH Regensburg. As their freshmen seminary takes place on the afternoon of the first day of studies - traditionally the only free time slot of first-year students - they minimize the "loss of lecture time" to zero. This program attempts to support transition from school to university, enable students to detect knowledge deficits on their own, initiate socialising as well as recap study regulations and deadlines. To achieve this, they employ self-reflection techniques, requiring students to write down their own targets, expectations and important results. However, this approach does not scale well. Hence, in a second run the organizers switched to a test form on learning behaviour in order to evaluate the individual learning type. Furthermore, they incorporated discussion groups, a presentation and a maths test. At the end, students are provided with a handout on self and time management strategies, and evaluate their success in small groups.

Another, fundamentally different approach was developed by Carnegie \& Browne (2014) at Victoria University of Wellington. They strove to develop an engineering culture, revised and created lectures and established a so-called pastoral service, accompanying students for several semesters. Through all these attempts, they significantly increased their students' retention rate in the engineering programs. Note that the pastoral service had a high impact on this success, as the pastoral care agent uncovered "barriers to student performance and (at times) [was able to] physically accompany them to the appropriate form of assistance". 


\subsection{Assessing First-semester Students' Competences}

In 2013 we developed a self-assessment Zehetmeier et al. (2014), which focusses on competences necessary to study Computer Science successfully. The test layout is based on the complementary estimation aid (KEH - Komplementäre Einschätzungs-Hilfen) developed by Eberle (2007). Competences we investigate into originate from Thurner (2014). Additionally, we developed a knowledge test Zehetmeier (2017) to get to know our students' initial level in important areas like basic math, computer theory and practice as well as several cognitive competences.

As well, we developed the skill profile of a model-student, which is based on a survey among lecturers in first-semester Computer Science courses on their expectations by Thurner et al. (2012). Combining model-student and self-assessment, we report to individual students how their current skill profile relates to lecturers' expectations. As well, we provide lecturers with an insight into their cohorts' competences.

\section{Organisation}

During our action day, which usually takes place in the first week of studies in winter semesters, we integrate the assessments described in section 3.2 into a series of team challenges, such as STOP WATCH, MAGIC CARPET, MARBLE RUN and MAKING A KNOT. Furthermore, we integrated three slots (welcome, competences during your studies, closing) where lecturers present their expectations, useful hints and their view on what it takes to study successfully. Table 1 provides a detailled schedule. Note that we try to alternate theoretical input, assessments and socialising, thus keeping a balance between the different types of acitivities.

\begin{tabular}{lll}
\hline Duration & \multicolumn{1}{c}{ Activity } & \multicolumn{1}{c}{ Place } \\
\hline $15 \mathrm{~min}$ & WELCOME & Lecture room \\
$15 \mathrm{~min}$ & STOP WATCH & Open space \\
$15 \mathrm{~min}$ & MAGIC CARPET & Open space \\
$45 \mathrm{~min}$ & SELF-ASSESSMENT & Lecture room \\
$15 \mathrm{~min}$ & & \\
$15 \mathrm{~min}$ & COMPETENCES DURING YOUR STUDIES & Lecture room \\
$30 \mathrm{~min}$ & MARBLE RUN & Open space \\
$75 \mathrm{~min}$ & KNOWLEDGE TEST & Lecture room \\
$25 \mathrm{~min}$ & MAKING A KNOT & Open space \\
$5 \mathrm{~min}$ & CLOSING & Lecture room \\
\hline
\end{tabular}

Table 1. Schedule of the first-semester action day. 
Most of the entry-phase programs are time and staff consuming. We tried to minimize the required number of lecturers and found an approach that can be performed mainly with student tutors. Nevertheless, there is always one person e.g. from scientific staff, organising (room management, preparing material and tests) and being responsible for everything.

The action day also requires some post processing. For example, tests are evaluated automatically and individual feedback is generated. Each student receives a PDF, showing individual results compared to lecturers' expectations. Furthermore, every lecturer receives an overview of his/her student cohort. This has to be prepared by the scientific staff as well.

\section{Elements of the Action Day}

Throughout the action day, tests are embedded in both theoretical input and team challenges, which we describe in the following.

\subsection{Theoretical Input}

As mentioned before, universities focus on other learning objectives than schools, addressing problem solving abilities rather than fact knowledge by heart. To help students to get aware of these differences, we explain the different types of tasks and learning objectives to our students, in terms of the revised Bloom's Taxonomy by Anderson (2001). This approach is continued throughout the first two semesters, e.g. in the lab assignments.

The main goal here is to increase awareness that various types of skills and tasks exist, each of which requires different ways of learning. First-semester students are usually very good at learning facts by heart. However, this is not what lecturers expect of them in the end-ofterm exams. As specified in Thurner (2016) only $10 \%$ of the exam questions ask for terms and definitions, as some sort of warm up to the exam. After that, the vast majority of tasks involves skills on higher Bloom levels, such as understanding a topic or choosing the correct approach out of several processes that would solve a given problem.

To create this awareness is a main goal of the theoretical input of this first-semester action day, which is primarily provided in the section COMPETENCES DURING YOUR STUDIES. 


\subsection{Team Challenges}

As researchers like Harris (2006) and Barefoot (1993) have shown that a feeling of togetherness can influence student retention in a positive manner, we integrated four team challenges into the action day. In order to increase the number of fellow students each students comes in contact with, we randomly create a new team for every challenge.

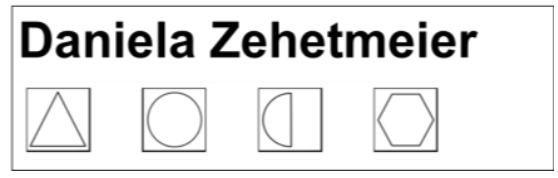

Figure 1. Name tag

To achieve this, we generate name tags (cf. Figure 1. Name tag) for the students. Underneath the name, each tag shows four symbols representing the four challenges. Posters showing a single symbol each are distributed in the open space. At the beginning of challenge n, students assemble at the poster that depicts the n-th symbol on their name tag. Thus, teams are newly assembled for each challenge.

\subsubsection{Stop Watch Klee (2006)}

In this challenge, the group of students forms a circle. One student receives the stop watch and talks about school background, weaknesses and strengths (often regarding subjects), hobbies and much more for 45 seconds. Then, the students hands the stop watch to the next person on the right, who in turn speaks for 45 seconds, and so on, until every student introduced him-/herself. Thus, students get to know fellow students and start to talk to each other. Furthermore, this shows students' expressiveness, self-assuredness and also humor.

It is important that every students speaks exactly for 45 seconds. Supervisors need to encourage shy students to speak, for example by giving hints for topics or asking questions. Additionally, they have to interrupt students that talk too much.

\subsubsection{Magic Carpet}

The magic carpet is represented by a canvas (approx. $1 \mathrm{~m}^{2}$ for 5 students). The game is applicable for up to 15 students and exhibits capacity for cooperating, teamwork and systematic thinking. All students of a team start standing on the canvas, which is spread on the floor. They are told that they had an accident while flying across the Atlantic Ocean on their magic carpets, so that the carpet is now flying upside down. In this position the carpet cannot accelerate and starts to drop slowly. In order to reach the land, the team needs to turn the magic carpet around. However, you cannot step from the magic carpet, as you will fall down into the sea. So the task is to turn the canvas around, without "falling off". 
The supervisor checks that all students remain on the canvas at any time. If not and if it is a small offence (e.g. brief touch of the floor) the student gets a handicap, for example an inflated balloon that has to be carried between the knees. In case of a big offence the punishment can go up to starting the process again. Supervisors should not be too critical during this game as it is more about having fun and communicating, rather than winning.

\subsubsection{Marble Run}

This challenge is all about creativity and teamwork. Every group of at maximum 8 students receives 4 DIN A3 and 6 DIN A4 sheets of cardboard, 2 glue sticks, 2 scissors and 3 marbles. The goal is to build a marble run that fulfills the following requirements: Robust design, self-supporting (not adhered to floor or wall), attractive design, group symbol integrated, well-defined finish, marble must run independently (only start impulse is allowed), marble must only run on the marble run (floor is not part of it).

Marble runs are rated according to the run time of the marble. Students have three trials, where the best one counts. If the marble gets stuck in the marble run, the run time is set to zero. Run time can be stopped while all students stand around a marble run. This increases the team spirit. Afterwards, the organiser prepares a ranking for the closing session.

\subsubsection{Making a Knot}

Making a knot demonstrates teamwork, conflict resolution, willingness to follow instructions and decisiveness. The game can be conducted with 6 to 16 students and varies in time. Students stand in a semicircle holding a rope with both hands. They now have to reproduce a knot that is shown to them, without letting go of the rope or letting the rope slide through their hands. Students are not allowed to touch the given knot.

\section{Evaluation}

Two months into the semester and thus two months after the action day, we conduct a survey among our first-year students. In this questionnaire, the majority of students agree that the action day helped them to get into contact with other students. Additionally, lecturers report that students are socially connected in a more intense way than before we started our action days. Furthermore, we observe that students that attended the action day flock together in study groups right from the first lecture.

We received much positive feedback on our assessments. Students appreciated the selfreflection process initiated by the assessments. Colleagues appreciated the results as highly informative and helpful Zehetmeier (2014). 


\section{Summary and Future Work}

In order to offer our students a better start into their new period of life at university, we designed an action day for first-semester students. The single activities of this action day can be used separately, but display the best effect when carried out together.

Positive feedback from students and lecturers shows that the action day increases student retention. At the same time, our approach is customisable, requires only few lecture hours and involves a minimal number of professional staff.

We started to develop other activities focussing on the later profession of the students, like a project simulation Thurner et al. (2015). This is another important step to help our students to reflect on and identify with their chosen course of studies.

\section{References}

Anderson, L. W., Krathwohl, D. R., \& Bloom, B. S. (2001). A Taxonomy for Learning, Teaching, and Assessing. A Revision of Bloom's Taxonomy of Educational Objectives (1 ed.). New, York: Longman.

Barefoot, B. O., \& Gardner, J. N. (1993). The freshman orientation seminar: Extending the benefits of traditional orientation. Designing successful transitions: A guide for orienting students to college, 141-153.

Carnegie, D. A., \& Browne, W. N. (2014). Factors that affect the design of a successful engineering programme: A case study. 2014 IEEE Global Engineering Education Conference (EDUCON), 62-68.

Diehl, A., Wolff, L., Fuhrmann, T., Niemetz, M., Mörtlbauer, S., \& Dirnberger, S. (2016). Compact Freshmen Welcome Seminar for Engineering Students. Procedia-Social and Behavioral Sciences, 228, 45-52.

Eberle, W. (2007). Das KEH-System und sein Interviewverfahren bei Personaleinstellungen. In F. Westermann (Ed.), Entwicklungsquadrat - Theoretische Fundierung und praktische Anwendungen, 45-57. Göttingen: Hogrefe.

Harris, B. A. (2006). The importance of creating a "sense of community". Journal of College Student Retention: Research, Theory \& Practice, pp. 83-105.

Klee, O. (2006). Spiele und Methoden für Workshops, Seminare, Erstsemestereinführungen oder einfach so zum Spaß. Accessed on [27.04. 2015]. Available under http://www. spielereader.org.

Reith, D., Bachmeier, C., \& Groß, I. (2015). Be an engineer right from the start. 2015 IEEE Global Engineering Education Conference (EDUCON), 249-254.

Rothe, I. (2015). Work in progress: Starter-project for first semester students to survey their engineering studies. 2015 IEEE Global Engineering Education Conference (EDUCON), $1-4$.

Standridge, C. R., Kundrat, M. E., \& Pedreros-Oviedo, C. S. (2006). Creating the Context for Learning Engineering: A Seminar for Freshmen. Proceedings. Frontiers in Education. 36th Annual Conference, 1-5. 
Thurner, V., \& Böttcher, A. (2012). Expectations and Deficiencies in Soft Skills -Evaluating student competencies in Software Engineering education. 2012 IEEE Global Engineering Education Conference (EDUCON), 1198--1204.

Thurner, V., Böttcher, A. C., \& Kämper, A. (2014, April). Identifying Base Competencies as Prerequisites for Software Engineering Education. 2014 IEEE Global Engineering Education Conference (EDUCON), 1069-1076.

Thurner, V., Böttcher, A., \& Schlierkamp, K. (2016, April). Aligning learning objectives and exams: Moving upwards on the expertise level stack. 2016 IEEE Global Engineering Education Conference (EDUCON), 455-462.

Thurner, V., Schlierkamp, K., Zehetmeier, D., \& Böttcher, A. (2015). Software engineering project simulation in student entry phase of computer scientists-to-be. 2015 IEEE Global Engineering Education Conference (EDUCON), 486-493.

Zehetmeier, D., Böttcher, A., \& Thurner, V. (2017, April). Design and Evaluation of a Test for Assessing CS-First-year Students' Cognitive Competences (accepted for publication). 2017 IEEE Global Engineering Education Conference (EDUCON).

Zehetmeier, D., Kuhrmann, M., Böttcher, A., Schlierkamp, K., \& Thurner, V. (2014, April). Self-Assessment of Freshmen Students' Base Competencies. 2014 IEEE Global Engineering Education Conference (EDUCON), 429-438. 